A R T I C ULO

\title{
LA LUCHA DE LAS MuJeres \\ eN AMÉrica LATINA: \\ Feminismo, Ciudadanía y Derechos
}

\author{
Por: Gloria Bonilla Vélez
}

Artículo Recibido: 13 de abril de 2007

Artículo Aceptado: 9 de junio de 2007

\section{RESUMEN}

Este articulo explora los diversos discursos generados acerca de las mujeres, del feminismo y del sufragismo en los años que se suceden desde los albores de las primeras reivindicaciones feministas hasta la época en que finalmente las organizaciones sufragistas conquistaron la igualdad de derechos políticos para las mujeres, y de cómo influyeron en la historia de la lucha por el sufragio femenino. Interesa ante todo el pensamiento de las mismas mujeres, las primeras que rompieron la tradición y empezaron a hablar y escribir para el público femenino sobre ellas mismas. Escribieron para proponer una nueva mujer, aunque en esa toma de la palabra las opiniones las dividieron en torno a asuntos tan álgidos como la educación, el voto, y el trabajo. Queremos mostrar como fue ese transito a la conquista de la ciudadanía. El artículo se divide en dos partes: una primera da cuenta de la lucha de las mujeres en América latina y la segunda se centra en el caso de Colombia.

Palabras Claves: Participación política, exclusión, feminismo, sufragio, movimiento de mujeres, liberalismo.

\begin{abstract}
The present article gives account of the theoretical and methodologic positions assumed in the investigation "innovating fatherhood in Cartagena de Indias. A relational analysis between I interpreted and the previous generation" for the understanding of the innovation in the fatherhood exercise and the construction of masculine identities of a Cartageneros men/father group which today they assume and practice a different fatherhood in relation to his previous generation, which was in favor noticeable clearly of patriarcales characteristics, presenting them like traditional families. The
\end{abstract}


article shows then, the approaches and the methodologic routes with which it has come working the study at issue, which tries to understand what happens and what happened in the life of some fathers so that today they present breaks and transitions in the exercise of the fatherhood and their identities of gender, (these understood as sociocultural constructions), from which they narrate of themselves in their vital stories.

\section{Key Words: Knowledge, biographical method, histories of life, narrative analysis, gender as investigation perspective.}

\section{Visionarias y Luchadoras. Movimientos de Mujeres y Propuestas Feministas}

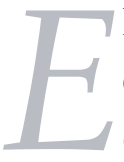
l país latinoamericano con más organización feminista en las primeras décadas del siglo XX fue Argentina, allí el aumento del número de mujeres en el mercado laboral fue desde sus inicios muy significativo. Asunción Lavrin sostiene: que el censo de 1914 mostró que en Buenos Aires las mujeres constituían el 16\% de la totalidad del trabajo industrial, empleadas principalmente (93.2\%) en el procesamiento de alimentos, vestuario, industrias químicas y empaquetadoras. Entre 1845 y 1941 el número de mujeres empleadas en el comercio se duplicó, el número de maestras aumento casi siete veces y casi se triplico el número de mujeres trabajando en profesiones de la salud. ${ }^{1}$ Visto así, estas mujeres vinculadas laboralmente engrosaran las filas del movimiento feminista anarquista y feminista socialista en lucha por la conquista de los derechos, porque si bien esta población femenina estaba excluida de los derechos políticos, el proceso de democratización consolidó el desarrollo y el surgimiento de organizaciones feministas que reclamaban la participación política de la mujer, así como la ampliación de los derechos civiles. Lavrin califica el periodo de 19191932 como los años dorados de la campaña feminista en Argentina. ${ }^{2}$

En el país austral, si bien existen algunas reivindicaciones aisladas anteriormente, la acción grupal comienza a principios del siglo XX. Las condiciones particulares del desarrollo argentino, marcada por profundas modificaciones vinculadas a la consolidación de un estado liberal y de su proyecto modernizador, inciden en la evolución de estas tendencias. Como indica Marcela Nari, el feminismo es tanto un emergente de un momento histórico-social concreto, como uno de sus agentes transformadores. ${ }^{3}$ Su surgimiento evidencia innegables influencias de los postulados y practicas de las organizaciones internacionales, que cristalizan tanto a nivel discursivo como en contactos personales y la constitución de asociaciones

\footnotetext{
${ }^{1}$ A. Lavrin: The ideology of feminism in the Souther Cone 19001940 Woodrow Wilson Center, 1986, pags 31, y ss.

2 A. Lavrin: "Mujeres y Feminismo en Argentina 1900-1940". Revista Mujeres, Santiago de Chile, 1998, pag 34 .

${ }^{3}$ M. Nari: "Feminismo y maternidad y los derechos de la mujer 1920-1940" presentado en las $V$ Jornadas de Historia de las mujeres $y$ de genero, Universidad Nacional de la Pampa,,La Pampa, septiembre de 1998.
} 
4 L. Calvera. Mujeres y Feminismo en Argentina, Grupo Editor Latinoamericano, Buenos Aires, 1990, M. C. Feijoo. "Las luchas feministas", en Todo es Historia, No 128, Buenos Aires, 1978.D. Barranco: Anarquismo, educación y costumbres de la Argentina de principios del siglo $X X$. Buenos Aires, Contrapunto, 1990. A. Martinez y G. Tejero. "Lucha de clases y Feminismo: Principios del siglo XX en Argentina". En: H. Garrido y C. Bravo: (compiladoras), Temas de Mujer y Perspectiva de Genero. IV Jornadas de Historia de las Mujeres y Estudios de Genero, Universidad Nacional de Tucumán, Tucumán, 1998. M. Molyneux. Movimientos de Mujeres en América Latina. Madrid, Ediciones Cátedra, 2003, pags 25-30. que aparecen como extensiones de las respectivas europeas. La formación de estas identidades tiende a concentrar los esfuerzos individuales en procura de objetivos comunes. Supone conciliar diferencias personales para arribar a un consenso pragmático que posibilite un accionar conjunto. Se constituyen, entre otras, el Consejo Nacional de Mujeres, La Unión Gremial Femenina, El Centro Socialista Feminista, El Centro de Universitarias Argentinas, El Centro Feminista, La Liga para los Derechos de la Mujer y el niño y la Liga Feminista de la Republica Argentina. ${ }^{4}$

Paulatinamente las organizaciones mencionadas van sumando adhesiones. Si bien Buenos Aires concentra estas actividades en su carácter de capital de la república, las mismas repercuten también en el interior de las provincias. Integrar un frente común les otorga visibilidad, permitiendo un alcance más amplio de sus mensajes. En el mismo sentido estos grupos propician la realización de reuniones con el fin de posibilitar intercambios intelectuales.

Siendo el feminismo una corriente de ideas y prácticas políticas sumamente heterogéneas, cada nucleamiento ostenta particularidades, unificándolos la intención manifiesta de modificar las condiciones de inserción social de las mujeres argentinas. La formación de asociaciones, la organización de congresos, la publicación de artículos periodísticos y la redacción de proyectos destinados a transformar los marcos legales que prescriben los derechos civiles y políticos, son algunas de las estrategias desplegadas con el fin de renovar las modalidades que asumen las relaciones entre los géneros.

El feminismo anarquista surgió en Buenos Aires en la década de 1890 en el contexto modelado por tres factores que distinguían a la Argentina entre los estados latinoamericanos de finales del siglo XIX y comienzos del XX: un crecimiento económico rápido, el flujo de grandes números de inmigrantes europeos y la formación de un movimiento laboral activo y radical. Desde la década de 1870 se abrieron oficinas especiales en Italia, España, Francia y Alemania para atraer a los inmigrantes a la Argentina con la promesa de tierras baratas, pasajes y préstamos. La respuesta en las áreas deprimidas de Europa fue positiva y la tasa de inmigración alcanzada no tuvo comparación con la de ningún otro lugar en el subcontinente.

El anarquismo en Argentina alcanza su pico en las primeras décadas del siglo XX y la historia anterior de este movimiento puede ser vista como un avance lento y muchas veces interrumpido hacia este clímax. La Voz de la Mujer apareció después 
de medio siglo de continua y tentativa actividad anarquista, y como una de las primeras expresiones de lo que llegaría a ser el anarquismo argentino en su mejor momento. La Voz de la Mujer pertenecía a la tendencia del comunismo anarquista ${ }^{5}$ europeo propagado por Kropotkin y Eliseo Reclus en Europa y Emma Goldman y Alexander Berkmann en los EEUU. Tanto el socialismo como el anarquismo se centraban en la clase trabajadora, pero también expresaban su simpatía por la emancipación de la mujer. Para 1880 en Argentina ya se empezaban a publicar a escritoras como Soledad Gustavo(Teresa Mañe) y Teresa Claramunt del mundo anarquista europeo y a Voltairine de Cleyre, Emma Goldman y otras del movimiento norteamericano, en sus editoriales ya aparecen criticas a la familia y apoyando el "feminismo" que ya era un termino común. El mayor impulso al feminismo anarquista provino de los activistas españoles y los exiliados italianos como Enrico Malatesta y Pietro Gori que apoyaron las ideas feministas en sus diarios y artículos. Es comprensible entender porque las feministas se sintieron atraídas por el anarquismo. Sus preceptos centrales acentuaban la lucha contra la autoridad, y el feminismo anarquista centraba sus energías en el poder ejercitado sobre las mujeres en el matrimonio y la familia, buscando la libertad de tener relaciones fuera de estas instituciones. La Voz de la mujer expresaba: "odiamos la autoridad porque aspiramos a ser personas humanas y no maquinas automáticas o dirigidas por la voluntad de "otro", se llame autoridad, religión o cualquier nombre. Ni Dios, ni patrón, ni marido". ${ }^{6}$

Ya en la década de 1890 el movimiento anarquista presentaba una serie de rupturas. La Voz de la Mujer y la Voz de Rochabol rápidamente perdieron terreno frente al auge del movimiento socialista que estaba mas sensible a las luchas de la clase trabajadora; en 1894 se funda el Partido Socialista Argentino comprometido con la participación electoral y la reforma laboral. Ante el repliegue de esta corriente feminista anarquista surge un nuevo feminismo que intentara dar respuesta a las demandas y reivindicaciones de las mujeres y se hará cargo de problemas como al alza de salarios, mejores condiciones de trabajo, etc. Se trata del feminismo del Partido Socialista. Mujeres como Cecilia Grierson, Alicia Moreau de Justo y Juana Rouco Buela lanzaron la lucha por la igualdad de derechos, mejores oportunidades educacionales, y la reforma del código civil, y al hacerlo redefinieron la política, la estrategia y el terreno de la lucha feminista.

Aunque el programa socialista apuntaba a lograr resultados más tangibles que el del anarquismo, carecía del radicalismo feminista ardiente que había formado parte de la militancia del anarquismo. Más importante aún es que su tendencia a derivar la opresión de las mujeres primariamente del capitalismo, o a verla

5 El comunismo
anarquista era una
fusióndeideassocialistas
y anarquistas. Bajo
el principio de "cada
uno, según sus
fuerzas; a cada uno
según su necesidad".
M. Molyneux: La voz
de la mujer. Periódico
comunista-anarquista.
Buenos Aires,
Universidad de Quilmes,
2002, pag 17.

anarquista comunismo fusióndeideas socialistas y anarquistas. Bajo erincipio de cada fuerzas; a cada uno según su necesidad". M. Molyneux: La $\mathrm{VOZ}$ de la mujer. Periódico comunista-anarquista. Universidad de Quilmes, 2002, pag 17 
como mediada por las prácticas discriminatorias del estado, los socialistas no desarrollaron, como los anarquistas, una critica radical de la familia, el machismo y el autoritarismo. Tampoco la sexualidad ocupo un lugar importante dentro del discurso feminista socialista.

En la década del treinta la agenda política de las feministas argentinas no solo era obtener el derecho a voto sino que atacaban la problemática mas amplia del colectivo femenino: medidas de protección para las embarazadas y sus hijos, mejoras en las condiciones de trabajo, con el golpe de Estado de 1930 estas agrupaciones se ven limitadas para su accionar., pero logran el derecho al voto en 1947.

Como se ve la irrupción de las corrientes anarquistas procedentes de ultramar fueron determinantes en la construcción de las ideas sobre la emancipación femenina y la critica a la sexualidad y a la familia. En la práctica el ideario anarquista que trajeron los miles de inmigrantes impulso la creación de sindicatos y formas de organización comunitaria. En México, Bolivia, Cuba, y Perú la predica anarquista también se dejo sentir. Grupos anarquistas colaboraron con los líderes de la revolución mejicana a través de los llamados "batallones rojos". El famoso Plan de Ayala de Emiliano Zapata es de inspiración libertaria. En Cuba durante la guerra de Independencia librada contra los Estados Unidos, los obreros anarquistas constituyeron un importante bastión de apoyo.

En Perú el proceso de industrialización permitió el ingreso de la mujer al trabajo productivo asalariado, incorporándose así a la lucha política y sindical. En 1905, el proletariado peruano inicio la conquista de la jornada de 8 horas. A pesar del bajo porcentaje de obreras la participación femenina fue significativa. En Junio de 1916, durante las manifestaciones de Guacho, Irene Salvador y Manuela Chaflajo, con otras tres obreras fueron asesinadas por la policía, dos años después en 1918, se conquistó la jornada de 8 horas para las mujeres y los menores de edad. En 1914 se había fundado la primera organización de mujeres "Evolución Femenina" Dirigida por Maria Jesús Alvarado, e integrada por mujeres profesionales y de clase media. En 1915 se aprueba el Proyecto de Ley -que había sido defendido por Evolución Femenina- que aprobaba que la mujer de la clase media accediese a la esfera social del trabajo., pues las capas populares ya se habían incorporado

${ }^{6}$ M Molyneux: La Voz de la Mujer. Periódico comunista-anárquico, Universidad Nacional de Quilmes, Buenos Aires, 2002 , pag 86 . al trabajo productivo. Todo este movimiento y la lucha por la igualdad jurídica de la mujer y la reforma al Código Penal, ocasionó que Maria Jesús Alvarado fuera deportada a Argentina. Años más tarde en 1919, el proletariado realizo un paro general en contra del costo de vida. Un grupo de mujeres en la manifestación 
desfiló bajo la consigna abajo los capitalistas. Viva la organización femenina. ${ }^{7}$

En 1936 se creó la primera Organización Femenina en el Perú que trato de unir la acción política con la lucha por reivindicaciones específicamente femeninas, como la igualdad de derechos sociales, la igualdad de salarios, la capacitación profesional, la creación de guarderías y el cambio de la situación jurídica de las mujeres. Acción Femenina fundada por Alicia del Prado. Por primera vez se unen mujeres comunistas, apristas e independientes. Por la lucha de objetivos comunes. En la década del 40 una organización estudiantil universitaria lucha por lograr el sufragio que se consigue en $1956 .^{8}$

${ }^{7}$ S. B. Guardia: Mujeres Peruanas. El Otro lado

En México durante el movimiento revolucionario de 1910 la incorporación de mujeres fue muy importante, no sólo como acompañantes de los hombres y Historia. Lima, Editora Humbolt, 1985, pag 72 realizando sus tareas tradicionales (cocinar, lavar y cuidar los hijos, entre otras) sino también actividades militares, y difundiendo las ideas revolucionarias; fueron espías, correos, enfermeras y colaboraron en los planes y proyectos Dolores Jiménez y Muro participo en la redacción del Plan Ayala de Emiliano Zapata9 .

Consecuencia de la revolución mejicana (1910-1917) fue la formación de una arena política renovada, en la cual el feminismo de corte liberal adquirió una dimensión política. "A partir de 1915 la facción constitucionalista, encabezada por Venustiano Carranza, inicio la creación de un nuevo orden político, se empezó a reconstruir espacios políticos a las fuerzas sociales contendientes durante el proceso revolucionario y busco satisfacer, algunas de las demandas del movimiento armado. Las reformas sociales y políticas impulsadas por el movimiento constitucionalista fueron diversas las hubo incluso con propósitos feministas". ${ }^{10}$

Dentro del feminismo constitucionalista, destaca Hermila Galindo, allegada a las altas esferas del poder revolucionario, impulso el proyecto feminista mas radical del momento e intento formar un movimiento de mujeres entre las militantes y simpatizantes de la facción revolucionaria de la que ella hacia parte. Defendió una educación igualitaria para hombres y mujeres, y pugnó por una reforma a la legislación civil que desterrara la doble moral de las relaciones entre los sexos. El marco ideológico de su feminismo fue el liberalismo, de ahí que un objetivo prioritario de su lucha fuera la igualdad plena de derechos ciudadanos- incluido el voto-para las mujeres.

La igualdad de los derechos electorales fue uno de los objetivos centrales del

8 E. de Lloc: La Mujer Moderna, Lima Marzo de 1950. A. M. Portugal: Hacia una comprensión del feminismo en el Perú, Lima, 1980.

9 G. Cano. "Las feministas en Campaña" en: Debate Feminista No 2 México Septiembre de 1991. G. Cano. "La ciudadanía de las mujeres: disyuntiva entre la igualdad y la diferencia sexual (México 1917-1953)" en M. Moscoso (comp.) Palabras del silencio. Las mujeres latinoamericanas y su historia, Quito, Abya-Yala, 1995. Anfer (comp.) Participación política de la mujer en México en el siglo $X X$, México, ICA-PRI, 1984. E. Tuñon. iTodas a Votar! Las mujeres en México y el derecho al voto 1917-1953. en: J. Andreo y S. B. Guardia. Historia de las Mujeres en América Latina. Universidad de Murcia, Murcia, 2002.

${ }^{10}$ G. Cano: "Revolución, Feminismoy Ciudadanía en México 1915-1940". En G. Duby y M. Perrot. Historia de las Mujeres. Tomo 9, Taurus, 1990, pag 301.

Palobrano. 8 Agosto/2007 
movimiento feminista. A ella estuvieron vinculadas tres figuras importantes cuya intervención en la vida pública las hizo más visibles que otras son ellas Hermila Galindo comprometida con el movimiento constitucionalista, Elvia Carrillo lucho por los principios socialistas y Refugio García militante comunista. Cada

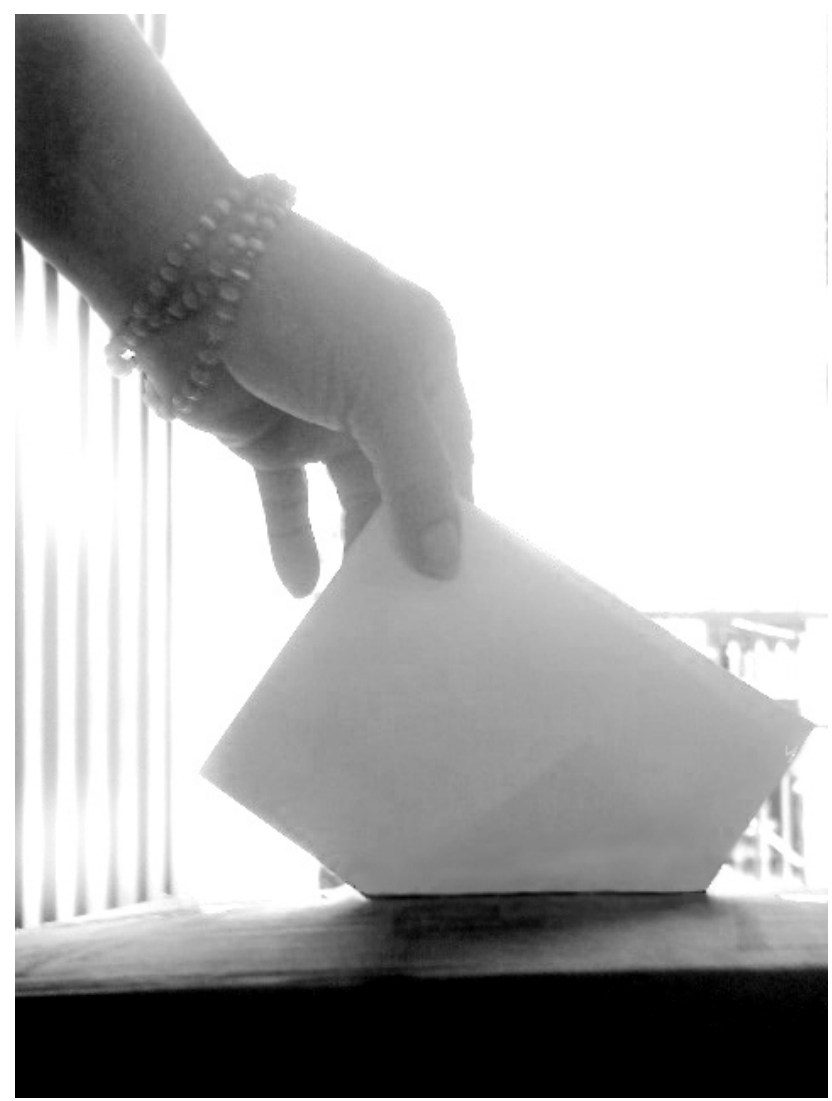

Foto: Juan Flórez Martínez, Universidad de Cartagena. una a su manera buscó la manera de movilizar y organizar las mujeres. Tanto Hermila Galindo como Elvia Carrillo se presentaron a las elecciones de sus provincias de 1918 y 1925, aunque habían ganado en las urnas por mayoría de votos los colegios electorales no reconocieron su triunfo.

El voto femenino en México va perdiendo interés en la opinión publica que tuvo en los veinte y treinta y es en 1953 cuando las mujeres mejicanas obtienen los plenos derechos políticos, Amalia Castilla Ledon funda la Alianza de Mujeres de México y con el apoyo del presidente saliente Miguel Alemán y Adolfo Ruiz Cortines el elegido por el PRI y las mujeres mejicanas alcanzan este derecho.

En Panamá, con el inicio de los trabajos del Canal en 1907 son muchos los norteamericanos que llegan al Istmo, y desde el principio se procura que los trabajadores tuvieran las mejores condiciones no solo físicas sino espirituales y se creara un ambiente de bienestar y disfrute. Se facilita el establecimiento de las familias, también llegan mujeres solteras a hacer diversa trabajos en el canal como secretarias, enfermeras, y también con la intención de que los hombres solos formaran hogares con ellas. Poco a poco van organizando clubes, salas de lectura, teatros, bibliotecas, escuelas dominicales, para 1906 ya había Cruz Roja donde las mujeres participaban activamente en la atención a los enfermos, En 1907 con la llegada desde Nueva York de Helen Varick Boswll se crea la Federación Nacional de Clubes Femeninos cuyo objetivo era lograr la domesticidad femenina, enfatizar en una vida domestica que procurara hogares felices a los hombres jóvenes. En 1907 la federación ya tenia 15 organizaciones femeninos en 1913 asciende a 25 hasta llegar a 58 en 1914 fecha de terminación de construcción del Canal y regreso a casa de los hombres, mujeres y personal norteamericano.

Panamá fue un caso especial entre las republicas latinoamericanas, nació como 
republica independiente con una constitución mucho más liberal que las restantes naciones latinoamericanas. Separada de Colombia por los Estados Unidos a través de una indemnización. La Constitución de 1904 elimino la referencia explicita a que sólo los varones tenían el derecho a la ciudadanía que tenía la constitución colombiana y aceptaba además el principio democrático del sufragio universal masculino, lo cual creaba una nueva contradicción ya que dificultaba enormemente la justificación de la discriminación de las mujeres a la ciudadanía. Fue particular, Panamá también porque desde los primeros años del siglo XX recibió una influencia directa de las organizaciones femeninas y del movimiento feminista norteamericano. Pero no por ello dejó de ser una república, en la que como los restantes países de Latinoamérica, la cultura compartida por siglos ponía en el debate sobre el feminismo y el sufragismo temas tales como la maternidad y la feminidad, con los que las feministas panameñas se enfrentaron. ${ }^{11}$

En Panamá el debate sobre el sufragio y los derechos de las mujeres se inicia en 1922. En ese momento ocurrieron dos hechos trascendentales que hacen estallar la polémica: el primero de ellos es la presentación del diputado Pérez Venero de su proyecto de ley sobre el sufragio femenino y el otro es la creación, casi paralelamente, en diciembre de ese año, del Grupo Feminista Renovación y el anuncio de la creación de la Sociedad Nacional para el Progreso de la Mujer. ${ }^{12}$

Además del sector de los liberales, el feminismo en Panamá tuvo otros aliados políticos como eran algunas agrupaciones e individualidades anarquistas y socialistas que se agitaban en el incipiente movimiento obrero. La Federación Obrera de Panamá en su programa de 1921 incluía la reivindicación del sufragio femenino. Pero no todo el movimiento obrero estuvo a favor del sufragio femenino, un sector influido por el anarquismo contrario a la lucha parlamentaria en su negativa aducía razones como que la mujer se convertiría en competidora y enfrentada al hombre con lo que se pondría en peligro la causa de las clases desvalida, la mujer no necesita el sufragio porque la apoya y protege la clase obrera.

El 20 de septiembre de 1923 se realiza el Primer Congreso Feminista Nacional y se crea el Partido Nacional Feminista y se postula para las próximas elecciones a Clara Gonzáles como diputada. En los años cuarenta la situación del voto femenino cambio radicalmente y se conquisto definitivamente la igualdad política en 1946, primero que en el resto de países de Latinoamérica donde será años después. Esta nueva situación se definió en poco tiempo debido a una serie de razones de orden internacional y nacional. Los Partidos organizados en el Frente Popular compuestos por los liberales más democráticos, los comunistas y los socialistas que defendían la reestructuración democrática del poder.

11 Y. Marco Serra. El Movimiento sufragista en Panamá y la construcción de la Mujer Moderna" En: Historia de los Movimientos de Mujeres en Panamá en el siglo $X X$. Universidad de Panamá, Panamá, 2002, pag 53.

12 E. Reyes Rivas. El trabajo de las mujeres en la historia de la construcción del Canal de Panamá 1881-1914. Panamá, Instituto de la Mujer. Universidad de Panamá, 2000, pag 46. 
13 Y. Marco. Mujeres que cambiaron nuestra historia: Mujeres parlamentarias en Panamá. Panamá, Universidad de Panamá, 2000. J. Santamaría: La mujer panameña y sus derechos políticos, 19201946. Panamá, Editorial Universitaria, 2000, pag 34

${ }^{14}$ F. Thébaud. "Mujeres, ciudadanía y estado en Francia durante el siglo $X^{\prime \prime}$. En: A. Aguado (comp.) Las mujeres entre la historia y la sociedad contemporánea. Valencia. Generalitat Valenciana, 1999, pags 13,15.
En 1946 se aprueba la Nueva Constitución en su articulo 97 "consagraba el derecho a la ciudadanía de todos los panameños mayores de veintiún años, sin distinción de sexo", instituyo otra serie de derechos que afectaban la situación de las mujeres y otros sectores desprotegidos de la sociedad: el Estado garantizaba los derechos de la niño y el niño hasta la adolescencia, decreto escuela primaria obligatoria, igualdad de salarios sin distinción de sexo, se prohibió el despido de la mujer embarazada, igualdad de los hijos e hijas habidos fuera del matrimonio. ${ }^{13}$

\section{Movimiento de Mujeres, Feminismo y Ciudadanía en Colombia}

Quienes se han interesado en las mujeres y el género como tema de estudio histórico han prestado atención a la política. Buena parte de la labor historiográfica se ha dedicado a examinar los movimientos políticos feministas que persiguieron la obtención de los derechos políticos formales, a rescatar del olvido la vida y obra de hombres y mujeres que propendieron por la igualdad de los sexos, y a denunciar los sistemas políticos, normativos e ideológicos que discriminaron a las mujeres. Es así como la legitimación y consolidación académica de los estudios de la mujer y el género, de la misma manera que sus debates y conceptos básicos tienen una deuda con la reflexión política feminista.

Dos elementos centrales de confluencia entre el liberalismo, la lucha de las mujeres y el feminismo tienen que ver con el reconocimiento pleno de la ciudadanía y el derecho a la educación. Sin embargo el tema de la ciudadanía para las mujeres en Colombia por parte de los liberales, estuvo acompañado de múltiples obstáculos. Los liberales tuvieron mucho repara a la hora de conceder el derecho al voto a las mujeres, pues pensaban que la mujer llevaría a la urna electoral la opinión de su marido, de su padre, de su hermano, o de su amante.

La ciudadanía es un aspecto fundamental de los derechos políticos y consiste en el conjunto de derechos, obligaciones y garantías públicas y privadas de que goza un grupo de la población que tiene la categoría de ciudadana, que le otorga oportunidades y prerrogativas en relación con el ejercicio del poder político y el control de las funciones públicas. Una de las expresiones de la ciudadanía es el ejercicio del sufragio, del derecho a elegir y ser elegido para los órganos de representación popular. La ciudadanía puede definirse de dos formas. Como una relación entre el Estado y los individuos, aquella condición por la que un Estado reconoce a sus miembros y les concede derechos que deniega a los no-ciudadanos. Como relación entre los individuos y el Estado, evoca la participación de éstos en los asuntos de la ciudad. ${ }^{14}$ Con esta definición, es claro que la ciudadanía 
es ante todo política y de lo que se trata es de comprender como y cuando las colombianas acceden a los derechos políticos, saber el derecho al voto y el derecho a ser elegidas y representar.

\section{Derechos Políticos de la Mujer: Los Ritmos del Sufragio}

Como dice, Magdala Velásquez el Estado Colombiano, como ente independiente del yugo colonial español, se adscribió principalmente a los lineamientos de la Revolución Francesa de 1789, que tenían por base teórica el reconocimiento de la libertad, la igualdad y la fraternidad de todos los hombres. Pero a pesar de esta proclamación teórica, en la práctica gozarían de ellas los propietarios, los alfabetas y los varones; era por tanto una democracia organizada no sólo por y para los propietarios sino por y para los varones. ${ }^{15} \mathrm{La}$ Constitución de la República de

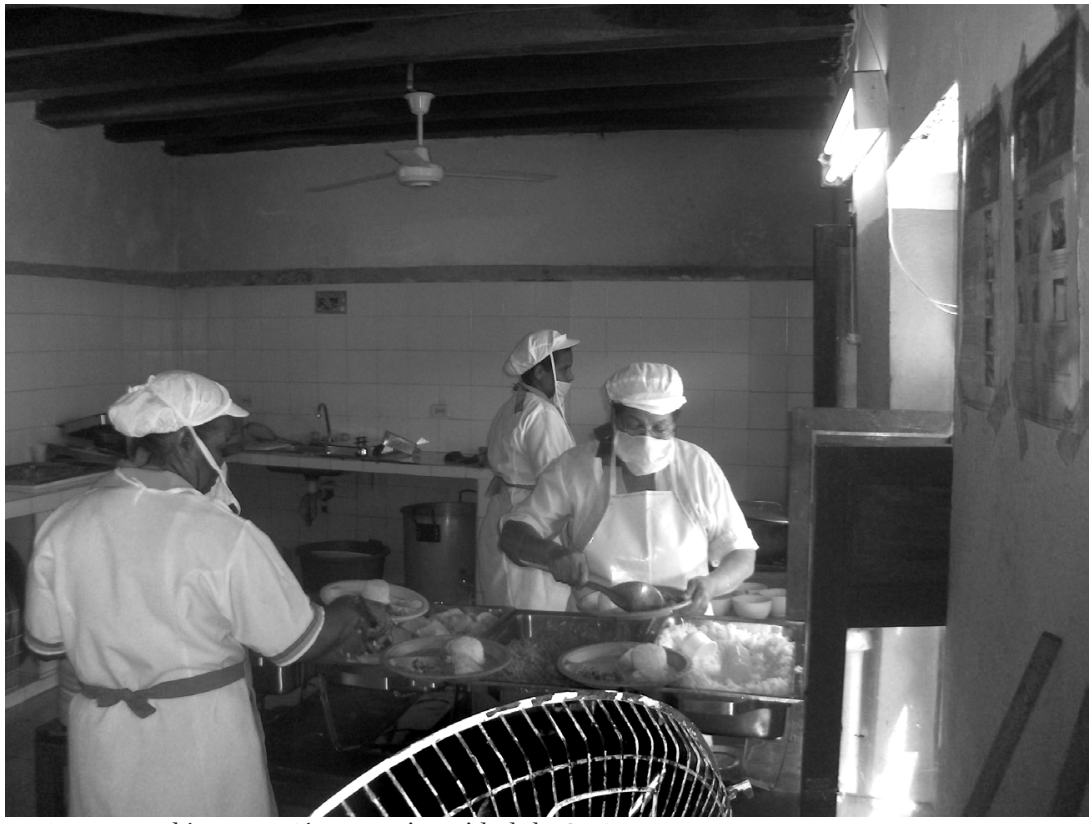

Foto: Juan Flórez Martínez, Universidad de Cartagena. Colombia de 1821 definía la calidad de ciudadano sin especificar el sexo, pero la cultura política no pensaba la posibilidad de la ciudadanía femenina, pero la cultura política no pensaba la posibilidad de la ciudadanía femenina. Sólo a partir de la Constitución de 1843 se introdujo la fórmula de que son "ciudadanos los granadinos varones", Constitución que rigió hasta mediados del siglo XX.

El régimen de la Regeneración en 1886 otorgo a la iglesia católica una serie de prerrogativas posteriormente desarrolladas en el concordato suscrito con el Vaticano en 1887. Entrego a la iglesia la soberanía del estado para regular el estado civil de las personas que profesaran la fe católica. Creo en 1888 el privilegio de la anulación del matrimonio civil celebrado antes, para quienes contrajeran matrimonio católico con otra persona. En 1924, mediante la ley Concha, que fue un desarrollo de los convenios concordatarios el Estado exigía a quienes fueran a contraer matrimonio civil apostatar públicamente de la fe católica. Esta norma estaba inscrita en el derecho canónico que consideraba al "matrimonio civil como un público y atroz concubinato". ${ }^{16}$

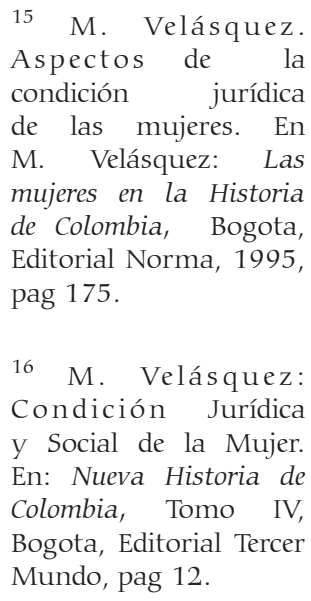

15 M. Velásquez. Aspectos de la condición jurídica de las mujeres. En M. Velásquez: Las mujeres en la Historia de Colombia, Bogota, Editorial Norma, 1995, pag 175 .

16 M. Velásquez: Condición Jurídica y Social de la Mujer. En: Nueva Historia de Colombia, Tomo IV, Bogota, Editorial Tercer Mundo, pag 12. 
17 M. Velásquez: op cit, pag 11.

${ }^{18}$ M. E. Wills Obregón: "Cincuenta años del sufragio femenino en Colombia. 1954: por la conquista del voto, por la ampliación de la ciudadanía de las mujeres" en Análisis Político, No. 53, Bogotá: IEPRI-UN, enero-marzo de 2005, p. 39-57.
La condición civil y jurídica de la mujer en Colombia era de una total dependencia del marido o del padre. El Código Civil colombiano consignaba que el marido debe protección a la mujer y la mujer obediencia al marido, el marido tiene derecho a obligarla a vivir con el y seguirle a donde quiera que traslade su residencia. La mujer por su parte, tiene el derecho a que el marido la reciba en su casa, el domicilio era del marido no de ella. Al casarse la mujer perdía la capacidad de manejar su dinero y sus bienes, dado que la ley le otorgaba al marido la administración exclusiva de los de la sociedad conyugal y los de la propiedad de la mujer. ${ }^{17}$

Además de todas las atribuciones masculinas sobre la legítima mujer, los juristas decidieron, en sus interpretaciones, ampliar la potestad marital a aspectos tales como la facultad de inspeccionar las relaciones y correspondencia del cónyuge y prohibirle amistades que según la opinión del marido fueran perjudiciales.

La instrucción de la mujer se reducía, pues, en los escasos sectores de la población que tenían acceso a ella, a la enseñanza dela religión, de la lectura y de la escritura, pocas nociones de historia y geografía y todos aquellos elementos que le permitieran cumplir con las obligaciones familiares, como bordado, costura y economía familiar. La educación buscaba mantener a la mujer en el ámbito de lo doméstico y se vinculaba a la formación de ciudadanos. Desde el feminismo, ya se planteaban cambios denunciando la incapacidad de la mujer. Las sistemáticas denuncias, sobre la subordinación de la mujer en el matrimonio, en términos de su nula autonomía económica, sugiere la existencia de un grupo de mujeres con conciencia feminista vinculadas a este propósito.

Como en la mayoría de naciones, el siglo xx se inicia en Colombia sin que las mujeres tengan el derecho al voto y a la participación política. Sin embargo, en contraste con otros países latinoamericanos, el voto se aprueba después de la Segunda Guerra Mundial, en lo que se puede ver como la tercera ola sufragista (1945-1955). ${ }^{18}$ Mientras en la segunda ola que se desenvuelve del final de la primera guerra mundial hasta 1944 se encuentran países como Ecuador, Chile, Brasil, Uruguay, Cuba o Panamá, Colombia se ubica casi al final de la tercera ola, luego de países como Argentina, México, Guatemala y Venezuela. Es por esta razón que se puede aseverar que el país, a pesar de tener una de los sistemas democráticos más ininterrumpidos del continente, fue de las últimas naciones latinoamericanas en aprobar el sufragio femenino. ¿Por qué la resistencia a incorporar a las mujeres en la competencia electoral?. La repuesta reside en los arreglos institucionales y las confrontaciones partidistas que caracterizaron 
la vida política hasta 'La Violencia', y que a su vez marca la estructura de las iniciativas feministas que se emprendieron durante ese período.

La frontera entre liberales y conservadores, fundada en cuestiones religiosas, intervendrá en todas las discusiones que se suscitan en torno al sufragio femenino: implícitamente, conceder el voto a las mujeres implicaba para los liberales exponerse a perder el poder. Ellos asumían que las mujeres, bajo la tutela de los sacerdotes, votarían en masa por el partido conservador. Por el contrario, la Iglesia y el partido conservador reaccionarían con ira e indignación frente a las propuestas de derechos civiles concedidos a las mujeres o a la educación mixta promovida desde finales de los treinta, pero se mostrarían más benévolos frente al voto femenino. ${ }^{19}$

Para mencionar los casos más conocidos recordemos cómo Ignacio Torres Giraldo, compañero de militancia y de vida de María Cano, se sentía con el derecho y la obligación de legislar sobre los modales y la vestimenta de la líder; ${ }^{20}$ o cómo Mercedes Abadía, líder primero del Partido Socialista Democrático (PSD) y luego miembro de la dirección central del Partido Comunista de Colombia (PCC), tendría que soportar que el buró central se inmiscuyera en su vida privada, ${ }^{21}$ hasta tal punto, que los conflictos que sostuvo con su compañero de militancia le costarían a ella que no a él, su posición política dentro del partido. Mercedes Abadía desde muy joven participó en huelgas y protestas de las recogedoras de café y para 1930 tomó parte activa en las luchas de los trabajadores azucareros del Valle del Cauca. Desde fines de los años veinte comenzó a distinguirse a escala nacional como líder obrera. Hizo parte del Comité Central del Partido Comunista., ejerció como activista en núcleos sindicales y dirigió incipientes organizaciones de mujeres, a pesar de las críticas que recibía de los militantes del Partido Comunista entre ellos su compañero Pedro Abella y de otros dirigentes que cuestionaban su conducta como compañera del dirigente sindical.

El proceso de construir alianzas entre las mujeres para conseguir los derechos políticos no fue fácil, y ello ya se hacia evidente desde el Congreso Femenino realizado en Bogota en 1930 donde frente a la educación de la mujer había discrepancias entre las asistentes, sobre el mismo caso de Mercedes Abadía posicionada como líder obrera, el historiador Medófilo Medina dice: "ella se constituyó en la expresión más clara del entrelazamiento en el movimiento sindical, de las reivindicaciones obreras con los objetivos específicos de la lucha de las mujeres, pero no faltaron las contradicciones con los lideres obreros" ${ }^{22}$

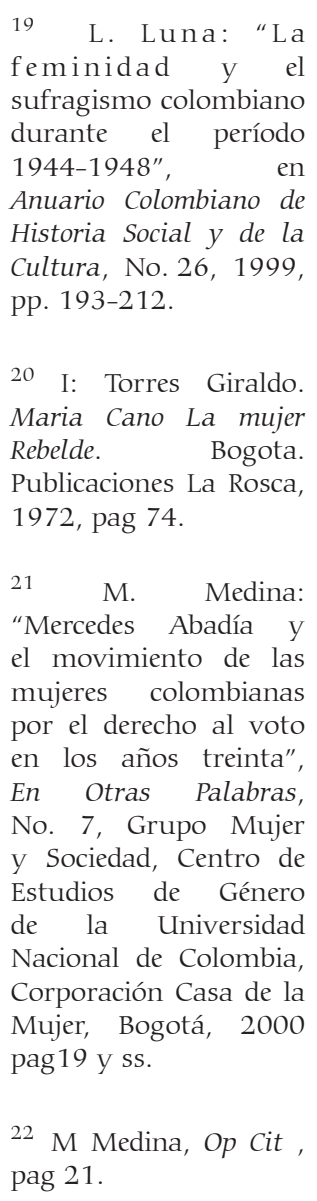
sufragismo colombiano durante el período 1944-1948", en Anuario Colombiano de Historia Social y de la Cultura, No. 26, 1999 , pp. 193-212.

20 I: Torres Giraldo. Maria Cano La mujer Rebelde. Bogota. Publicaciones La Rosca, 1972, pag 74 .

21 M. Medina:
"Mercedes Abadía y
el movimiento de las
mujeres colombianas
por el derecho al voto
en los años treinta",
En Otras Palabras,
No. 7, Grupo Mujer
Y Sociedad, Centro de
Estudios de Género
de la Universidad
Nacional de Colombia,
Corporación Casa de la
Mujer, Bogotá, 2000
pag19 y ss.
22 M Medina, Op Cit,
pag 21.




\section{Las Mujeres Hablan, Luchan y se Organizan}

En la década del veinte, antes de la victoria electoral del partido liberal en 1930, varias mujeres y hombres empezaron a introducir en la agenda del debate público la cuestión de las capitulaciones matrimoniales (potestad marital) y, en 1932, ya bajo el gobierno del presidente Enrique Olaya Herrera y luego del IV Congreso Internacional Femenino promovido por Georgina Fletcher —otra mujer excepcional-, se aprobaría la ley 28 que le otorgó a la mujer el derecho de disponer libremente de sus bienes, contraer autónomamente deudas, realizar otras transacciones financieras, y comparecer por sí misma ante la justicia. ${ }^{23} \mathrm{~A}$ pesar de que el sufragio estaba dentro de la agenda de reclamos, este derecho no obtuvo los apoyos necesarios para convertirse en ley.

Además de Georgina Fletcher, la voz de Ofelia Uribe de Acosta se haría sentir en el Congreso antes mencionado. Ella y otras mujeres presionarán por el derecho a la educación —bachillerato clásico y acceso a la universidad- que será aprobado en 1933 mediante un decreto ejecutivo. Tres años más tarde, en 1936, como parte de la reforma constitucional de Alfonso López Pumarejo, las mujeres adquieren el derecho a ocupar cargos públicos, paradójicamente sin haber obtenido sus

$23 \quad$ M. Velásquez: y Social de la Mujer. En Nueva Historia de Colombia, pag 34.

24 Palabras de Lucila Rubio de Laverde en el II Congreso Femenino realizado en Bogotá el 23 de mayo de 1946 en: L. Luna: "La feminidad y el sufragismo colombiano durante el período 1944-1948", op. cit. (1994) pag 34.

${ }^{25}$ L. Luna: “La feminidad $y$ el sufragismo colombiano durante el período 1944-1948", Op. Cit (1994). Así como Letras y Encajes sugiere una idea de feminidad delicada y centrada en las tareas domésticas, Agitación Femenina, por el contrario, trae a la mente una identidad combativa no dispuesta a dejarse encerrar en las cuatro paredes del hogar. plenos derechos políticos.

Ahora bien, este movimiento de mujeres que luchaban por el sufragio femenino no era ideológicamente homogéneo. A pesar de que todas las que militaban en la causa feminista compartían en ese momento una visión maternalista de la mujer — «el deber para con la familia es nuestro natural y principal deber»—, ${ }^{24}$ unas percibían el hogar como el único espacio legítimo de realización femenina y sólo estaban dispuestas a defender su derecho al voto sin exigir más enmiendas a los arreglos del momento, mientras otras, apoyándose en un concepto de ciudadanía amplia, exigían educación, derechos saláriales y acceso a cargos públicos. Las primeras expresarían sus posiciones en la revista Letras y Encajes, fundada en Medellín en 1925, y promoverían la creación de una Escuela de Domesticidad; las segundas, bajo la dirección de Ofelia Uribe de Acosta, publicarían en los cuarenta Agitación Femenina. ${ }^{25}$

El movimiento emancipatorio iniciado en 1930, impugno las bases sobre las cuales se sostenía la posición de la mujer, dando lugar a tres tipos de reivindicaciones: el manejo de los bienes por la mujer casada, acceso a mayor nivel educativo y el derecho al sufragio. Reivindicaciones que hacían parte también del movimiento feminista. La critica a la exclusión política de las mujeres, su no participación 
política en el gobierno estuvo como punto nodal en la agenda del movimiento sufragista desde 1930 hasta 1954.

En abril de 1948, se celebra la IX Conferencia Panamericana, que dio origen a la Organización de los Estados Americanos OEA. Allí se tenía como objetivo la aprobación de mecanismos internacional, en las América, para hacer realidad la concesión de los derechos civiles y políticos de las mujeres. La Liga de Acción Feminista Colombiana, envió una carta donde denunciaba el trato desigual y discriminatorio del estado Colombiano que negaba los derechos civiles y políticos a las mujeres. ${ }^{26}$

En este contexto la violencia desatada después del asesinato de Jorge Eliécer Gaitan el 9 de abril, el movimiento de las mujeres entró al parecer en receso frente a la crueldad de la confrontación. En medio de esta situación se continua aunque tímidamente el debate sobre el voto femenino. Ofelia Uribe de Acosta y varias de sus antiguas compañeras vuelven a manifestarse públicamente durante el gobierno del General Rojas Pinilla. Fundan el periódico La Verdad dirigido, gerenciado y escrito por mujeres. A pesar de las dificultades el contexto internacional era favorable al voto para ese entonces en América Latina ya varios países había aprobado el voto a la mujer. En el periodo de la dictadura de Gustavo Rojas Pinilla (1953-1957) se inicio un periodo de participación de las mujeres y el camino a la campaña sufragista se ve despejado para que la Asamblea Nacional Constituyente de 1954 se nombraran a dos mujeres, esmeralda Arboleda liberal y Josefina Valencia, conservadora, con el objetivo de evaluar y presentar el proyecto de Acto Legislativo sobre la Ciudadanía de las Mujeres. El 25 de agosto de 1954 fue aprobado mediante el acto legislativo No 3. En el plebiscito de 1957, que contó con la participación de las mujeres que ya habían adquirido plenos derechos se ratifico el otorgamiento de la ciudadanía a las mujeres. ${ }^{27}$

\begin{abstract}
26 L. Luna. "Condición social de las mujeres, discursos colombianos y el sujeto sufragista 1930-1957. En: Gabriella Dalla Corta y Javier Laviña. Relaciones sociales e identidades en América. Barcelona, Universitat de Barcelona, 2004, pags 155-169. M. Peláez. Derechos políticos $y$ ciudadanía de las mujeres en Colombia. Universidad de Antioquia, 2004. Magdala Velásquez. $O p$ Cit, pag 36 y ss.
\end{abstract}

27 L. Jaramillo. "Feminismo y luchas políticas: Anotaciones sobre la doble militancia". En: M. León. La realidad colombiana. Debate sobre la mujer en América Latina y el Caribe. Bogota, ACEP, 1982, pag 77 y ss. Y. Solano Regionalización y Movimiento de Mujeres. Bogota, Universidad Nacional, 2006. M. Velásquez. Derechos de las mujeres. Voto femenino $y$ reivindicaciones políticas. Credencial Historia, Octubre 1999, pag 7 .

Merecen una especial mención Juana Julia Guzmán nació en Corozal (Sucre) 
28 Y. Solano. Regionalización $\quad y$ Movimiento de Mujeres, pag 60.D. Díaz. Juana Julia Guzmán. La Robatierra. En: Otras Palabras, No 7, Bogota, Universidad Nacional, 2000, pag 23.

29 D. Casas. Betsabe Espinosa: Lider obrera y popular. En Círculos Obreros, Medellín, 1990. P. Buritica. Betsabe Espinosa: Resistencia obrera a la explotación y el abuso sexual. En Otras Palabras, No 7, Bogota, Universidad Nacional, 2000. en 1892, de origen humilde desde niña trabajo como clasificadora de tabaco, en 1916 se unió al socialista italiano Vicente Adamo llegado a la región del Sinú a principios del siglo XX; el amor y las ideas los comprometieron en una serie de luchas de los campesinos de Córdoba y Sucre. En 1918 funda la Sociedad de Obreros y Artesanos de Cordoba y El Baluarte Rojo de Lomagrande y la Sociedad de Obreras de Redención de la Mujer. ${ }^{28}$ Otras mujeres bailadoras de fandango, lavanderas, fritangueras, cocineras como Pacha Ferias, Agustina Medrano, Antonia Espitia, Marcelina Agamez, Mercedes Vidal, y Josefa González acogieron su convocatoria y participaron en el proceso colectivo de campañas antialcohólicas, horarios de trabajo de los tres ochos (ocho horas de trabajo, ocho de educación y ocho de descanso), fortaleció el comité de mujeres en la ANUC en los años 70. Murió en 1975 a la edad de 85 años.

Una figura femenina dentro de la clase obrera fue Betsabe Espinosa conocida dirigente de la Huelga de Fabricato en la ciudad de Medellín, en 1920, proponía la formación de escuadrones femeninos para protegerse de los esquiroles. Un grupo de obreras paralizan las actividades en demanda de aumentos saláriales, la destitución de los administradores que pretendían imponer un "trato de capataces" y el cese del abuso sexual que de ellas se hace; también piden que sea abolida la arbitraria prohibición de usar calzado, pues a causa de ésta han contraído diversas enfermedades, y además piden el derecho a un tiempo para consumir alimentos en la hora del almuerzo. ${ }^{29}$

\section{BIBLIOGRAFIA}

ALEGRE, María. (2002). "El voto de las mujeres en la Argentina"En: Mujeres ausentes Miradas Presentes, Universidad de Chile, Santiago de Chile.

ANFER, Jennifer. (comp.) (1984).Participación política de la mujer en México en el siglo XX, México, ICA-PRI.

CALVERA, Luisa. (1990). Mujeres y Feminismoen Argentina, Grupo Editor Latinoamericano, Buenos Aires.

CANO, Gabriela. (1995). "La ciudadanía de las mujeres: disyuntiva entre la igualdad y la diferencia sexual (México 1917-1953)” en M. Moscoso (comp.) Palabras del silencio. Las mujeres latinoamericanas y su historia, Quito, Abya-Yala.

Septiembre de 1991.

"Las feministas en Campaña" en: Debate Feminista No 2 México (1990). “Revolución, Feminismo y Ciudadanía en México 19151940".En G. Duby y M. Perrot. Historia de las Mujeres. Tomo 9, Taurus. 
BARRANCOS, Dora. (1990). "El contrafeminismo del feminismo anarquista"En: Anarquismo, educación y costumbres de la Argentina de principios del siglo XX. Buenos Aires, Contrapunto.

DE LLOC, Edna. La Mujer Moderna, Lima Marzo de 1950.

DÍAZ, D., GUZMÁN, Juana Julia.(2000) La Robatierra. En: Otras Palabras, No 7, Bogota, Universidad Nacional.

FEIJOO, María. (1978). "Las luchas feministas", en Todo es Historia, No 128, Buenos Aires.

FRANCO, Jean. (1999). La literatura hispanoamericana desde la independencia hasta hoy. Instituto Mora, México.

GUARDIA DE MIRO, Elena.(1922) "Habla la mujer Panameña" en El Tiempo, 21 de Diciembre.

GUARDIA, Sara. (1985). Mujeres Peruanas. El Otro lado de la Historia. Lima, Editora Humbolt.

G. DALLA CORTA Y J. LAVIÑA. Relaciones sociales e identidades en América. Barcelona, Universitat de Barcelona, 2004, pags 155-169.

LAVRIN, Asunción, (2002). Génesis del sufragio femenino en América Latina. En: Eugenia Rodríguez. Un siglo de luchas femeninas en América Latina Universidad de Costa Rica, San José, 2002.

(1998). "Mujeres y Feminismo en Argentina 1900-1940". Revista Mujeres, Santiago de Chile, pag 34.

(1986). The ideology of feminism in the Souther Cone 1900-1940

Woodrow Wilson Center, 1986.

LUNA, Lola. (1994). "La feminidad y el sufragismo colombiano durante el período 1944-1948", Hojas de Warmi No 8. Universitat de Barcelona. (1994)

. (2003). Los movimientos de mujeres en América Latina y la renovación de la historia política. Univalle.

MARCO SERRA, Yolanda. (2002). El Movimiento sufragista en Panamá y la construcción de la Mujer Moderna" En: Historia de los Movimientos de Mujeres en Panamá en el siglo XX. Universidad de Panamá, Panamá.

. (2002). "Ser ciudadana en Panamá en 1930". En: Eugenia Rodríguez. Un siglo de luchas femeninas en América Latina. Universidad de Costa Rica.

MARTÍNEZ, Ann Y TEJERO, Gabriela, (1998). "Lucha de clases y Feminismo: Principios del siglo XX en Argentina". En:. H. Garrido y C. Bravo: (compiladoras), Temas de Mujer y Perspectiva de Genero. IV Jornadas de Historia de las Mujeres y Estudios de Genero,

Palobrano. 8 Agosto/2007 
Universidad Nacional de Tucumán, Tucumán.

MEDINA, Med6filo. "Mercedes Abadía y el movimiento de las mujeres colombianas por el derecho al voto en los años treinta", En Otras Palabras, No. 7, Grupo Mujer y Sociedad, Centro de Estudios de Género de la Universidad Nacional de Colombia, Corporación Casa de la Mujer, Bogotá

MIRANDA, Mercedes. (2002). Las Organizaciones Femeninas en la Zona del Canal 1907-1930. En Historia del Movimiento de Mujeres en Panamá en el siglo XX, Universidad de Panamá, Panamá.

MOLYNEUX, Marianne. (2002). Ni Dios, ni patrón ni marido Feminismo Anarquista en Argentina. Presentación. La voz de la Mujer. Periódico Comunista-Anárquico, 1896-1897. Universidad Nacional de Quilmes, Buenos Aires.

NARI, Marcela. (1998). "Feminismo y maternidad y los derechos de la mujer 19201940" presentado en las $V$ Jornadas de Historia de las mujeres y de genero, Universidad Nacional de la Pampa.

PELÁEZ, M. (2004). Derechos políticos y ciudadanía de las mujeres en Colombia. Universidad de Antioquia.

PORTUGAL, Ana María, (1980). Hacia una comprensión del feminismo en el Perú, Lima.

RAMOS, María. “iMadres de la revolución?. Las mujeres y los movimientos sociales españoles 1900-1930", en G. Duby y M. Perrot. Historia de las Mujeres en Occidente, Tomo 5.

RASCóN, María. (1979). "La mujer y la lucha social en la historia de México". En: Cuadernos Agrarios No 9, México.

REYES, Ema. (2000). El trabajo de las mujeres en la historia de la construcción del Canal 1881-1914. Panamá, Instituto de la Mujer, Universidad de Panamá.

SOLANO, Y. (2006). Regionalización y Movimiento de Mujeres. Procesos en el Caribe Colombiano. Bogotá, Universidad Nacional.

THÉBAUD, Francoise (1999). "Mujeres, ciudadanía y estado en Francia durante el siglo XX". En: A. Aguado (comp.) Las mujeres entre la historia y la sociedad contemporánea. Valencia. Generalitat Valenciana.

TORRES GIRALDO, Ignacio. (1972). Maria Cano La mujer Rebelde. Bogota. Publicaciones La Rosca.

TUÑON, Elena. (2002). iTodas a Votar! Las mujeres en México y el derecho al voto 1917-1953. en: J. Andreo y S. B. Guardia. Historia de las Mujeres en América Latina. Universidad de Murcia, Murcia.

VELÁSQUEZ, Magdala. (1998). "Condición Jurídica y Social de la Mujer". En Nueva Historia de Colombia, Tomo IV. Editorial Tercer Mundo. 
(1995). Aspectos de la condición jurídica de las mujeres. En M. Velásquez: Las mujeres en la Historia de Colombia, Bogota, Editorial Norma, pag 175.

. (1995). "La republica liberal y la lucha por los derechos civiles y políticos de las mujeres". En : M. Velásquez (comp.) Las mujeres en la Historia de Colombia, Bogota, Editorial, Norma.

VILLARREAL, Norma. (1994). "Movimientos de mujeres y Participación política en Colombia 1930-1991" En: L. Luna y N. Villarreal. (eds) Movimientos y participación política en Colombia 1930-1991. Barcelona, Universitat de Barcelona.

VOS OBESO, Rafaela. (1999). Mujer, Cultura y Sociedad en Barranquilla 1900-1930. Barranquilla, Universidad del Atlántico.

WILLS OBREGÓN, María. (2005). "Cincuenta años del sufragio femenino en Colombia. 1954: por la conquista del voto, por la ampliación de la ciudadanía de las mujeres" en Análisis Político, No. 53, Bogotá: IEPRI-UN.

\section{BIOGRAFIA}

\section{GLORIA BONILLA VÉLEZ}

Profesora del Programa de Historia. Universidad de Cartagena. Candidata a Doctora y Becaria de la Universidad Pablo de Olavide Sevilla. 